\title{
Spatiotemporal Evolution and Features of Net Carbon Sink of Farmland Vegetation in Chongqing, China
}

\author{
Lin Zhu*, Wenzhuo Li, Yuan Huang, Jingyan Li \\ School of Political Science and Public Administration, Southwest University, Chongqing 400715, China
}

Corresponding Author Email: z12013@swu.edu.cn

https://doi.org/10.18280/ijsdp.150212

Received: 17 June 2019

Accepted: 2 January 2020

\section{Keywords:}

Chongqing, farmland vegetation, net carbon sink (NCS), net carbon sink strength (NCSS), carbon absorption, carbon emissions

\begin{abstract}
To promote sustainable development of agriculture, it is critical to reduce carbon sources and increase carbon sinks in farmland ecosystem by rationalizing the measures of agricultural management. This calls for scientific evaluation of net carbon sink (NCS) and its spatiotemporal evolution of farmland vegetation in a region. Taking 38 districts/counties of Chongqing, China as objects, this paper estimates the farmland vegetation NCS of Chongqing, based on statistics of crop yields and farmland inputs in 2000-2017. Then, geographical techniques were employed to analyze the features, regional difference and spatial evolution of NCS in Chongqing and its districts/counties. The main results are as follows: (1) From 2000 to 2017, the NCS and NCS strength (NCSS) of farmland vegetation in Chongqing both increased with fluctuations. The carbon sink, carbon emissions and carbon absorption increased across the board. The evolution of farmland vegetation can be divided into a wavy decline phase from 2000 to 2006, and a gradual increase phase from 2006 to 2017. (2) The source/sink structure of farmland vegetation in Chongqing remained stable in 2000-2017. The main sources are pesticide and tillage, and the main sinks are corn, rice, vegetables and oil crops. (3) In term of space, the farmland vegetation NCS and its center of gravity concentrated in the west zone and northeast zone. In general, the farmland vegetation of Chongqing boasts a strong carbon sink function; the west zone and northeast zone have the highest farmland vegetation NCSs; the west zone is the demonstration region of NCSS improvement.
\end{abstract}

\section{INTRODUCTION}

The carbon balance of the ecosystem has continued impacts on the environment [1], society and economy [2]. Low-carbon development is the only path towards a resource-saving and environment-friendly society [3]. As an important part of terrestrial ecosystem, the farmland ecosystem provides a huge carbon pool [4]. Agriculture can both emit and absorb carbon dioxide $\left(\mathrm{CO}_{2}\right)$ [5], whereas industry is a pure emitter [6]. Agricultural soil acts either a carbon sink or carbon source, which slows down or speeds up climate change [7]. On the one hand, farmland vegetation absorbs large amounts of $\mathrm{CO}_{2}$ through photosynthesis and stores them in crops; on the other hand, the carbon is returned to the soil by straw mulching.

From 1900 to 2009, the crops in China absorbed a total amount of 525.6-676.13 total graphitic carbon ( $\mathrm{TgC})$, revealing the carbon-sink function of farmland vegetation [8]. To promote sustainable development, it is important to design and implement a reasonable system of carbon reduction policies. Such a system requires scientific measurement of the following indices of farmland vegetation: carbon absorption, carbon emissions, net carbon sink (NCS), and net carbon sink strength (NCSS) of farmland vegetation [9].

Foreign scholars have paid more attention to carbon pools of forest [10-12] than carbon sources/sinks in agricultural or farmland system. But the latter is arousing a growing interest in the academic circle. The relevant studies either focus on macro levels like country level $[13,14]$ and provincial level, or target micro issues like soil carbon $[15,16]$. For example, Kay et al. [17] held that agroforestry creates carbon sinks while enhancing the environment in agricultural landscapes. Focusing on Brazil, Russia, India, China and South Africa (BRICS), Balsalobre-Lorente et al. [18] demonstrated that agricultural activities induce carbon emissions, which in turn suppresses economic growth. Lv et al. [19] found the interannual changes in the interaction between grazing and warming. Taking the Lower Fraser Valley, Canada for example, Rallings et al. [20] suggested that the versatility of agricultural landscapes promotes agricultural carbon sinks. Jat, et al. [21] proved through experiments that, to protect soil aggregates, intensive management must adapt to local conditions, and advocated conservation agricultural practices, such as zero tillage, crop residue management and proper rotation. Based on evidences from Germany, Vos et al. [22] demonstrated that agronomic management can increase the carbon sink capacity of soil surface. Funes et al. [23] discovered that the organic carbon stock of surface soil is mainly influenced by climate, soil texture, and agricultural variables, while that of bottom soil is mainly affected by soil texture, clay content, soil type and bedrock depth. Hertwich and Peters [24] calculated the carbon footprint of Luxemburg and 72 other countries, using the multi-regional input-output (MIRO) model. Robertson et al. [25] recognized that the agricultural emissions of $\mathrm{CO}_{2}$, nitrous oxide $\left(\mathrm{N}_{2} \mathrm{O}\right)$ and methane $\left(\mathrm{CH}_{4}\right)$ contribute greatly to global greenhouse gases (GHGs). 
Chinese scholars have mainly studied the carbon footprint of farmland soil and farmland ecology, but did not probe deep into the changes of net carbon sink in farmland vegetation [26]. Meanwhile, much research has been done on the effectiveness of agricultural carbon emissions [27], the development of lowcarbon agriculture, and low-carbon agricultural production. However, there is little report on the district/county level.

To make up for the gap, this paper attempts to describe and analyze the changes in NCS of agriculture on the district/county level in an accurate, clear and detailed manner. For this purpose, the spatial scale was further refined, and spatial analysis instrument was adopted to systematically measure the spatiotemporal distribution of district/countylevel agricultural NCS in Chongqing, China.

Firstly, the authors discussed about the estimation of the NCS of farmland vegetation, and estimated the NCS of farmland vegetation of Chongqing and its districts/counties between 2011 and 2017. Then, the time variation in district/county-level NCS of farmland vegetation was illustrated and examined based on time series and spatial method, aiming to disclose the law of spatiotemporal evolution of farmland vegetation NCS in Chongqing

\section{STUDY AREA AND DATA SOURCES}

\subsection{Study area}

Located in the middle reaches of the Yangtze River, Chongqing (N: $28^{\circ} 10^{\prime}-32^{\circ} 13^{\prime}$; E: $105^{\circ} 11^{\prime}-110^{\circ} 11^{\prime}$ ) is a mountainous city of southwestern China. The altitude of the terrain gradually rises from the west to the east. The subtropical monsoon climate brings lots of precipitation.

Covering an area of $8.24 \times 104 \mathrm{~km}^{2}$, Chongqing has a total of 38 districts/counties. Among them, 37 districts/counties are partially engaged in agriculture, and only Yuzhong District is fully urbanized. The districts/counties differ greatly in economic level. The urbanized district serves as a driving engine for the many rural districts/counties

Chongqing has a long history of agriculture, which involves a large portion of its population. The main crops include rice, wheat, rapeseed, sugar cane, fruits and vegetables. Besides agriculture, forestry, animal husbandry and fishery are all highly developed.

\subsection{Data sources}

The 38 districts/counties of Chongqing were taken as the research objects. The research data were mostly collected from Chongqing Statistical Yearbooks 2011-2018, the statistical data of the districts/counties, and the vector map of Chongqing urban planning. The collected data cover the carbon sink indices of farmland vegetation in 2000-2018 (e.g. the yield and planting area of 12 crops), and the agricultural production conditions (e.g. pesticide consumption, fertilizer consumption and sown area) that affect carbon emissions.

\section{METHODOLOGY}

According to United Nations Framework Convention on Climate Change (UNFCC), source refers to any process or activity which releases a GHG (e.g. $\mathrm{CO}_{2}$ ), an aerosol or a precursor of a GHG into the atmosphere; sink means any process, activity or mechanism which removes a greenhouse gas, an aerosol or a precursor of a greenhouse gas from the atmosphere.

On this basis, the difference between carbon sink and carbon source can be defined as the net carbon sink (NCS), a metric of the gap between the absolute values of carbon sink and carbon source.

According to the types of relevant carbon sinks and sources, agricultural production activities can be divided into two broad categories, namely, carbon emissions activities and carbon absorption activities. The former mainly includes ordinary production, irrigation, soil decomposition, livestock and poultry breeding, and straw burning. The latter consists of biomass, dead organic matter, and soil absorption.

In this research, agricultural carbon sinks/sources specifically refer to the carbon emissions and absorption, which take place in the agricultural production related to farmland vegetation.

\subsection{NCS estimation}

This paper defines the NCS of farmland vegetation as the difference between the carbon absorption and carbon emissions in crop growth period [6]. The carbon absorption in crop growth period can be estimated from the yield, carbon absorption rate, water content, economic coefficient, and rootshoot ratio of the crop [28]. The carbon emissions in crop growth period can be derived from the carbon emissions on different paths in agricultural production activities, namely, tilling machines, fertilizers, and pesticides [1].

The NCS can be estimated by the following formula:

$$
C_{t}=\sum C_{d}=\sum\left[Q_{i} \times C_{i} \times\left(1-W_{i}\right) \times\left(1+R_{i}\right)\right] \div H_{i}
$$

where, $C_{t}$ is the total carbon absorption of regional crops $(\mathrm{t}) ; i$ is the serial number of crops; $C_{d}$ is the carbon absorption of a crop (t); $Q_{i}$ is the yield of crop $i(\mathrm{t}) ; C_{i}$ is the ratio of $C d$ to $C_{t}$ (\%); $W_{i}, R_{i}$ and $H_{i}$ are the water content, root-shoot ratio and economic coefficient of crop $i$, respectively (\%).

This paper selects 12 main crops from Chongqing to estimate the carbon absorption. The relevant indices of the selected crops are listed in Table 1.

In farmland system, carbon absorption (sink) and emissions (source) occur at the same time. The carbon emissions of farmland vegetation can be converted from those of agricultural production activities. The carbon emissions coefficients used for the conversion are listed in Table 2.

Thus, the carbon emissions can be estimated by the following formula:

$$
E_{t}=E_{c}+E_{y}+E_{m}+E_{j}+E_{g}+E_{f}+E_{e}
$$

where, $E_{c}=G_{c} \times a: E_{c}$ is the carbon emissions in fertilizer production and application; $G_{c}$ is the consumption of fertilizers; $\mathrm{a}=0.8956 \mathrm{~kg} / \mathrm{kg}$;

$E_{y}=G_{y} \times b: E_{y}$ is the carbon emissions in pesticide production and application; $G_{y}$ is the consumption of pesticides; $\mathrm{b}=4.9341 \mathrm{~kg} / \mathrm{kg}$;

$E_{m}=G_{m} \times c: G_{m}$ is the consumption of agricultural films; $c=5.18 \mathrm{~kg} / \mathrm{kg}$;

$E_{j}=G_{j} \times d: E_{j}$ is the indirect carbon emissions of the fossil fuels consumed to produce the electricity needed for irrigation; $G_{j}$ is the area of effectively irrigated farmland; $d=266.48 \mathrm{~kg} / \mathrm{hm}^{2}$; 
$E_{g}=G_{g} \times e: E_{g}$ is the direct and indirect carbon emissions of the electricity consumed by agricultural machinery; $G_{g}$ is the diesel consumption of agricultural machinery; $e=0.5927 \mathrm{~kg} / \mathrm{kg}$.

$E_{f}=G_{f} \times h: E_{f}$ is the carbon emissions induced as the organic carbon pool of the soil is damaged by tillage; $G_{f}$ is the sown area of crops; $\mathrm{h}=312.6 \mathrm{~kg} / \mathrm{hm}^{2}$.

$E_{e}=\left(S_{e}{ }^{*} d\right)+\left(W_{e} * f\right): E_{e}$ is the direct and indirect carbon emissions of the diesel consumed by agricultural machinery; $S_{e}$ is the planting area of crops $\left(\mathrm{hm}^{2}\right) ; W_{e}$ is the total power of agricultural machinery; $d=16.47 \mathrm{~kg} / \mathrm{hm}^{2} ; f$ is the sown area of crops $=0.18 \mathrm{~kg} / \mathrm{kW} ; h=312.6 \mathrm{~kg} / \mathrm{hm}^{2}$.

On this basis, the NCS, denoted as $C_{n e t}$, can be estimated by:

$$
C_{\text {ent }}=C_{t}-E_{t}
$$

where, $\mathrm{Ct}$ and Et are the carbon absorption and emissions of farmland vegetation, respectively.

Next, the NCSS, denoted as $\mathrm{C}_{\mathrm{q}}$, can be estimated by:

$$
C_{q}=C_{\text {ent }} \div S_{g}
$$

where, $C_{q}$ is the NCSS, a.k.a. the carbon sink per unit of sown area $\left(\mathrm{t} / \mathrm{hm}^{2}\right) ; \mathrm{S}_{\mathrm{g}}$ is the sown area of crops $\left(\mathrm{hm}^{2}\right)$.

\subsection{Analysis of spatial evolution}

The ArcGIS was adopted to identify the spatial distribution features of district/county-level farmland vegetation NCS in Chongqing. The spatial distributions of 2000, 2006 and 2008 were selected for comparison, with the aim to disclose the regional features of agriculture and guide the agricultural development in each district/county.

The moving center of gravity model was introduced to study the spatial evolution of farmland vegetation NCS in Chongqing. The spatial coordinates of the center of gravity of each object can be computed by:

$$
\begin{aligned}
& X=\sum P_{u} x_{u} \div \sum P_{u} \\
& Y=\sum P_{u} y_{u} \div \sum P_{u}
\end{aligned}
$$

where, $\mathrm{X}$ and $\mathrm{Y}$ are the longitude and latitude of the center of farmland vegetation NCS in Chongqing; $\mathrm{Pu}$, $\mathrm{xu}$ and yu are the $\mathrm{NCS}$, longitude and latitude of district/county $u$, respectively.

Then, the moving distance of the center from year $u$ to year $\mathrm{v}$, denoted as Du-v, can be calculated by:

$$
D_{u-v}=R \times \sqrt{\left(X_{v}-X_{u}\right)^{2}+\left(Y_{v}-Y_{u}\right)^{2}}
$$

where, $\left(X_{v}, Y_{u}\right)$ and $\left(X_{v}, Y_{u}\right)$ are the coordinates of the center of farmland vegetation NCS in year $\mathrm{u}$ and year $\mathrm{v}$, respectively; $\mathrm{R}=111.11$ is the coefficient to convert geographical coordinates into planar coordinates $(\mathrm{km})$.

Table 1. The main indices of the selected crops

\begin{tabular}{ccccc}
\hline Name & Carbon absorption rate & Water content & Economic coefficient & Root-shoot ratio \\
\hline Rice & 0.414 & 0.12 & 0.450 & 0.6000 \\
Wheat & 0.485 & 0.12 & 0.400 & 0.3933 \\
Corn & 0.471 & 0.13 & 0.400 & 0.1558 \\
Sorghum & 0.450 & 0.12 & 0.350 & 0.1393 \\
Beans & 0.450 & 0.13 & 0.340 & 0.1292 \\
Tuber crops & 0.423 & 0.70 & 0.700 & 0.1750 \\
Oil crops & 0.450 & 0.10 & 0.250 & 0.0400 \\
Fiber crops & 0.450 & 0.15 & 0.3560 & 0.2915 \\
Sugar crops & 0.450 & 0.85 & 0.500 & 0.4151 \\
Tobacco leaf & 0.450 & 0.90 & 0.550 & 0.3175 \\
Vegetables & 0.450 & 0.90 & 0.600 & - \\
Fruits & 0.450 & 0.700 & - \\
\hline
\end{tabular}

Note: The parameters were extracted from Tian et al. [27]; the root-shoot ratio of soybean was taken as that of beans; the root-shoot ratio of tuber crops was obtained from Miao et al. [29]; the parameters of rapeseeds were taken as those of oil crops; the parameters of sugar crane were taken as those of sugar crops; the parameters of melons and strawberry were taken as those of fruits; the root-shoot ratios of vegetables and fruits were not considered, due to the complex varieties of these plants.

Table 2. Carbon emissions coefficients of agricultural production activities

\begin{tabular}{cccc}
\hline Sources & Carbon emissions coefficient & Unit & References \\
\hline Fertilizers & 0.8956 & $\mathrm{~kg} / \mathrm{kg}$ & Tian Yun et al. \\
Pesticides & 4.9341 & $\mathrm{~kg} / \mathrm{kg}$ & Tian Yun et al. \\
Agricultural films & 5.18 & $\mathrm{~kg} / \mathrm{kg}$ & Tian Yun et al. \\
Irrigation & 266.48 & $\mathrm{~kg} / \mathrm{hm}^{2}$ & West et al. \\
Diesel & 0.5927 & $\mathrm{~kg} / \mathrm{kg}^{2}$ & Tian Yun et al. \\
Tillage & 312.6 & $\mathrm{~kg} / \mathrm{hm}^{2}$ & Wu Fenlin et al. \\
Agricultural machinery & 16.47 & $\mathrm{~kg} / \mathrm{hm}^{2}$ & \\
& 0.18 & $\mathrm{~kg} / \mathrm{kW}$ & \\
\hline
\end{tabular}

\section{RESULTS AND ANALYSIS}

\subsection{Overall features of NCS}

According to the above estimation methods and indices, the carbon absorption, carbon emissions and NCS of farmland vegetation in Chongqing between 2000 and 2017 were calculated, and compiled into a number of figures (Figures 12) and a table (Table 3 ).

As shown in Figure 1, the NCS and NCSS of farmland vegetation in Chongqing increased between 2000 and 2017 with some fluctuations. The growths were prominent: $33.23 \%$ 
for NCS, and 41.84\% for NCSS. From 2000 to 2017, the NCS of farmland vegetation rose from 3.772 to 5.026 million $\mathrm{t}$, while the NCSS increased from 1.50 to $2.12 \mathrm{t} / \mathrm{hm}^{2}$. Both NCS and NCSS reached the peak values in 2017. The minimum NCS was 3.285 million $t$ in 2006, and the minimum NCSS was $1.33 \mathrm{t} / \mathrm{hm}^{2}$ in 2001 .

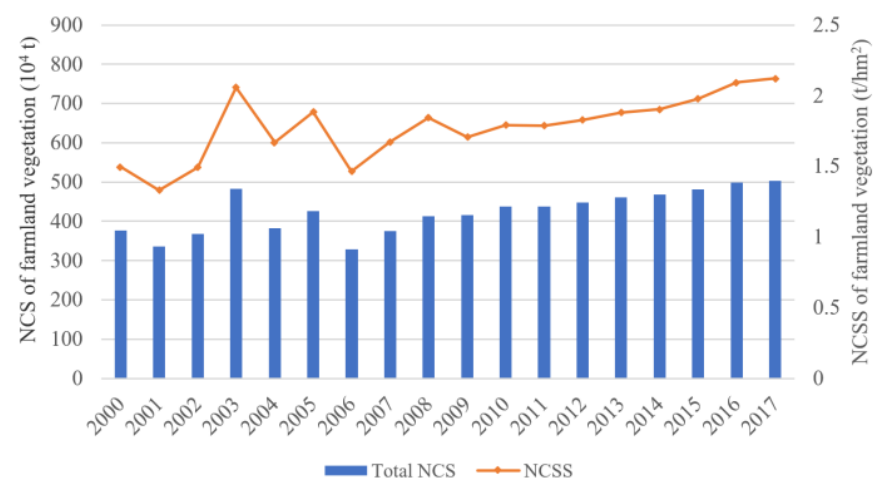

Figure 1. Variations in NCS and NCSS of farmland vegetation in Chongqing (2000-2017)

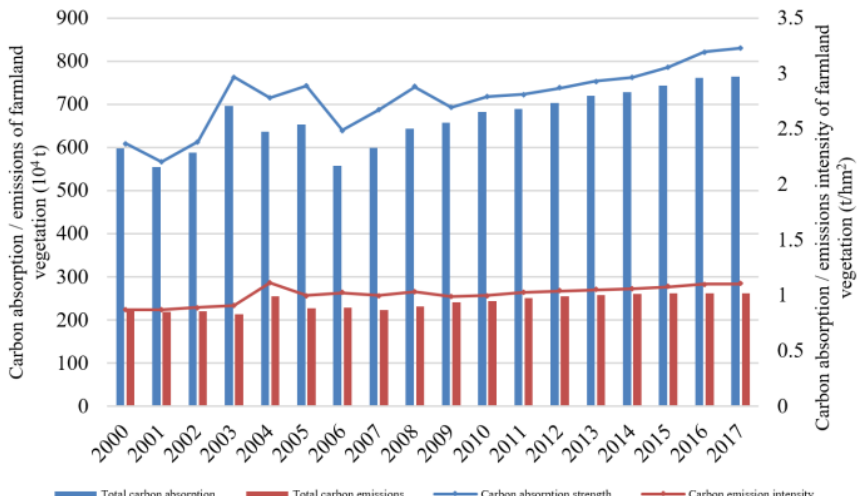

Figure 2. Variations in carbon absorption and emissions of farmland vegetation in Chongqing (2000-2017)

Overall, the NCS of farmland vegetation evolved in two phases: wavy decline and gradual increase. The first phase lasts from 2000 to 2006, where the NCS of farmland vegetation fluctuated several times. The second phase starts from 2006, where the NCS gradually rose from the lowest level.

As shown in Figure 2, the carbon emissions and carbon emissions strength of farmland vegetation in Chongqing both increased slowly. From 2000 to 2017, the total carbon emissions of farmland vegetation grew by $18.89 \%$ from 2.2019 to 2.6176 million $t$, while the carbon emissions strength surged by $26.57 \%$ from 0.87 to $1.10 \mathrm{t} / \mathrm{hm}^{2}$. The maximal and minimal carbon emissions appeared as 2.6208 million $t$ in 2016 and 2.1375 million $t$ in 2003, respectively; the maximum and minimal carbon emission strengths were observed as $1.11 \mathrm{t} / \mathrm{hm}^{2}$ in 2014 and $0.87 \mathrm{t} / \mathrm{hm}^{2}$ in 2001 , respectively.

The carbon absorption and carbon absorption strength of farmland vegetation in Chongqing also exhibited a continuous growth. From 2000 to 2017, the total carbon absorption of farmland vegetation increased by $27.95 \%$ from 5.9744 to the peak of 7.6440 million $\mathrm{t}$, while the carbon absorption strength soared by $36.21 \%$ from 2.36 to the peak of $3.23 \mathrm{t} / \mathrm{hm}^{2}$. The minimal carbon absorption was found in 2001 (5.5456 million t). Starting from 2006, the trend of carbon emissions strength became increasingly similar to that of carbon absorption strength of farmland vegetation.

\subsection{Sink/source structure}

Table 3 lists the sink/source structure of farmland vegetation in Chongqing (2000-2017). It can be seen that the sink structure remained stable from 2000 to 2017. In terms of perennial medians, corn, rice, vegetables and oil crops account for $31 \%, 25 \%, 13 \%$ and $10 \%$ of the sink structure, respectively, in the said period. Together, the four crops take up nearly $80 \%$ of the sink structure, and the proportion was gradually rising.

The source structure was also rather stable in the said period. In terms of perennial medians, fertilizer and tillage both contributed greatly to carbon emissions, taking up 33\% and $41 \%$ of the source structure, respectively. The combined contribution of the two variables surpassed $74 \%$, and slowly decreased from then on.

Table 3. The sink/source structure of farmland vegetation in Chongqing (2000-2017)

\begin{tabular}{|c|c|c|c|c|c|c|}
\hline \multirow{2}{*}{ Year } & \multicolumn{3}{|c|}{ Sinks } & \multicolumn{3}{|c|}{ Sources } \\
\hline & Corn & Rice & Vegetables & Oil crops & Fertilizers & Tillage \\
\hline 2000 & $28 \%$ & $28 \%$ & $10 \%$ & $8 \%$ & $29 \%$ & $49 \%$ \\
\hline 2001 & $30 \%$ & $27 \%$ & $11 \%$ & $8 \%$ & $30 \%$ & $48 \%$ \\
\hline 2002 & $30 \%$ & $27 \%$ & $11 \%$ & $9 \%$ & $30 \%$ & $47 \%$ \\
\hline 2003 & $26 \%$ & $37 \%$ & $9 \%$ & $9 \%$ & $30 \%$ & $46 \%$ \\
\hline 2004 & $31 \%$ & $26 \%$ & $10 \%$ & $10 \%$ & $27 \%$ & $51 \%$ \\
\hline 2005 & $31 \%$ & $26 \%$ & $10 \%$ & $10 \%$ & $31 \%$ & $45 \%$ \\
\hline 2006 & $32 \%$ & $22 \%$ & $12 \%$ & $11 \%$ & $31 \%$ & $44 \%$ \\
\hline 2007 & $34 \%$ & $27 \%$ & $11 \%$ & $8 \%$ & $34 \%$ & $41 \%$ \\
\hline 2008 & $33 \%$ & $27 \%$ & $12 \%$ & $9 \%$ & $34 \%$ & $41 \%$ \\
\hline 2009 & $32 \%$ & $25 \%$ & $14 \%$ & $10 \%$ & $34 \%$ & $41 \%$ \\
\hline 2010 & $32 \%$ & $25 \%$ & $15 \%$ & $10 \%$ & $34 \%$ & $41 \%$ \\
\hline 2011 & $32 \%$ & $23 \%$ & $16 \%$ & $11 \%$ & $34 \%$ & $40 \%$ \\
\hline 2012 & $32 \%$ & $23 \%$ & $17 \%$ & $11 \%$ & $34 \%$ & $40 \%$ \\
\hline 2013 & $31 \%$ & $23 \%$ & $17 \%$ & $11 \%$ & $34 \%$ & $40 \%$ \\
\hline 2014 & $30 \%$ & $22 \%$ & $18 \%$ & $12 \%$ & $33 \%$ & $40 \%$ \\
\hline 2015 & $30 \%$ & $22 \%$ & $18 \%$ & $13 \%$ & $33 \%$ & $40 \%$ \\
\hline 2016 & $30 \%$ & $22 \%$ & $19 \%$ & $13 \%$ & $33 \%$ & $41 \%$ \\
\hline 2017 & $30 \%$ & $22 \%$ & $20 \%$ & $14 \%$ & $33 \%$ & $41 \%$ \\
\hline Median & $31 \%$ & $25 \%$ & $13 \%$ & 10 & $33 \%$ & $41 \%$ \\
\hline
\end{tabular}




\subsection{Spatial distribution of NCS}

This subsection investigates the carbon emissions, carbon absorption and farmland vegetation NCS of each district/county in Chongqing, laying the basis for rational measures of carbon emissions. The Yuzhong District was not considered in the investigation. The carbon emissions, carbon absorption and farmland vegetation NCS of the remaining 37 districts/counties in 2000-2017 were measured. The NCS and NCSS data of 2000, 2016 and 2017 were imported to ArcGIS to plot the spatial evolution map of the farmland vegetation NCS in Chongqing. The map was used to analyze how the farmland vegetation NCS evolved in time and space.

The 38 districts/counties of Chongqing were divided into four economic zones: main city zone, west zone, northeast zone, southeast zone. The main city zone covers Yuzhong District, Dadukou District, Jiangbei District, Shapingba District, Jiulongpo District, Nan'an District, Beibei District, Yubei District, and Banan District; the west zone covers Fuling District, Changshou District, Jiangjin District, Hechuan District, Yongchuan District, Nanchuan District, Qijiang District, Dazu District, Bishan District, Tongliang District, Taongnan District and Rongchang District; the northeast zone covers Wanzhou District, Kaizhou District, Liangping District, Chengkou County, Fengdu County, Dianjiang County, Zhongxian County, Yunyang County, Fengjie County, Wushan County, and Wuxi County; the southeast zone covers Qianjiang District, Wulong District, Shizhu County, Xiushan County, Liyang County, and Pengshui County.

\subsubsection{Spatial features of NCS}

In terms of space (Figure 3), there was obvious regional difference of farmland vegetation NCS in Chongqing. In 2000, the high NCS mainly existed in most districts/counties of west zone and a few districts/counties of northeast zone. In 2006, fewer districts/counties of west zone had high NCS. In 2017, northeast zone had more high-NCS districts/counties than other zones. The west and northeast zones were the major contributors of NCS in Chongqing. In 2017, 47.32\% of carbon absorption in field vegetation of Chongqing occurred in the west zone, and $33.74 \%$ took place in northeast zone. Together, the two zones accounted for $81.06 \%$ of carbon absorption in field vegetation of Chongqing. By contrast, the proportions of southeast zone and main city zone were merely $0.14 \%$ and $0.53 \%$, respectively. In addition, the top 16 districts/counties in farmland vegetation NCS all come from west and northeast zones.

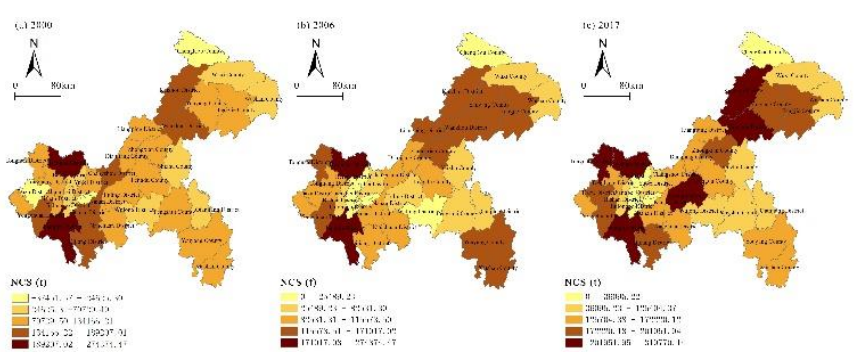

Figure 3. Spatial evolution of farmland vegetation NCS in Chongqing

In 2017, the top ten districts/counties in farmland vegetation NCS consisted of 5 districts/counties from west zone and five from northeast zone. The top district/county was Hechuan District $(31,980,000 \mathrm{t})$, followed by Tongnan District
$(31,350,000 \mathrm{t})$, Jiangjin District $(30,280,000 \mathrm{t})$ and Fuling District $(27,550,000 \mathrm{t})$. Nan'an District $(9,000 \mathrm{t})$ came at the bottom of the ranking of farmland vegetation NCS, behind Jiangbei District $(9,200 \mathrm{t})$, Dadukou District $(2,400 \mathrm{t})$, and Shapingba District $(6,500 \mathrm{t})$. The NCS of the top district/county (Hechuan District) was 349.58 times of that of the bottom district/county (Nan'an District).

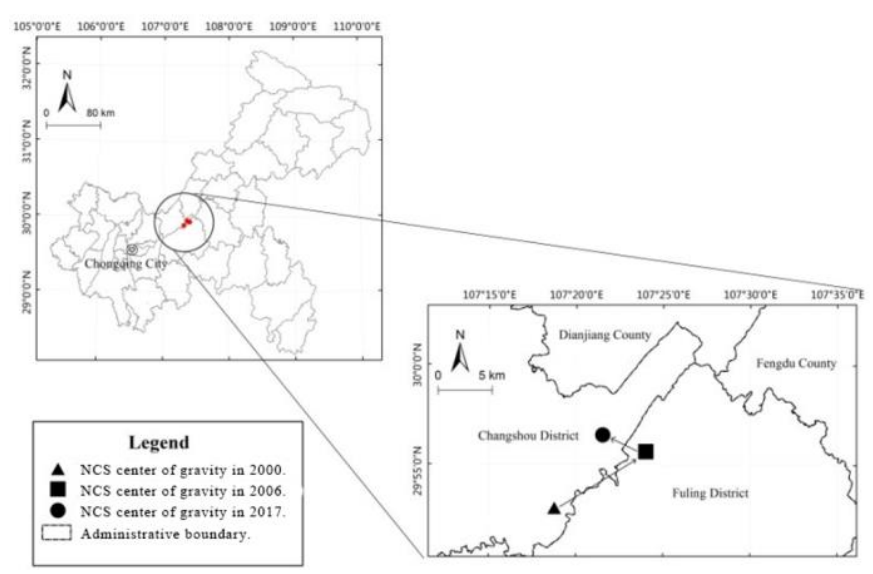

Figure 4. Shift in NCS center of gravity in Chongqing

As shown in Figure 4, the NCS center of gravity shifted from Changshou District in 2000, to Peiling District in 2006 and returned to Changshou District in 2017. The center of gravity always fell within the west zone. Therefore, the west zone is the focal point of farmland vegetation NCS in Chongqing. Over the 18 years, the center of gravity moved by $11.04 \mathrm{~km}$ in $2000-2006,4.83 \mathrm{~km}$ in $2006-2017$, and $8.50 \mathrm{~km}$ in 2000-2017. In general, the moving distance for the center of gravity was relatively stable, with only a slight change, and the center of gravity remained in the west zone.

\subsubsection{Spatial features of NCSS}

In terms of space (Figure 5), there was also obvious regional difference of farmland vegetation NCSS in Chongqing. The four zones were ranked as west zone $>$ northeast zone $>$ southeast zone $>$ main city zone by the NCSS.

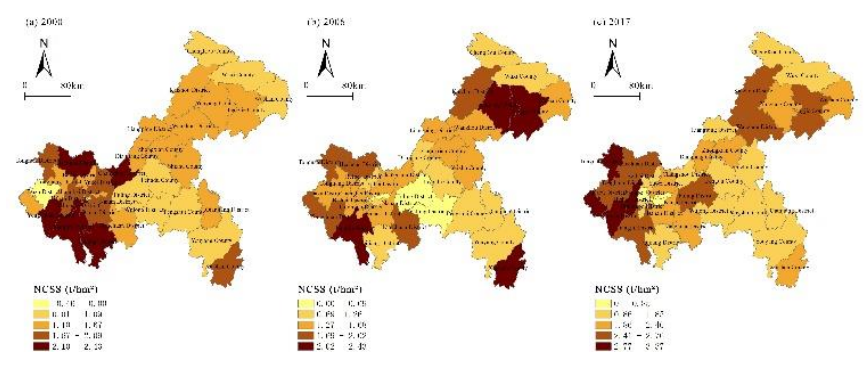

Figure 5. Spatial evolution of farmland vegetation NCSS in Chongqing

As shown in Figure 6, the top ten districts/counties in farmland vegetation NCSS in 2017 all belong to west and northeast zones. Tongnan District had the highest NCSS (3.37t/hectare), followed by Yongchuan District, Rongchang District, and Bishan District. Nan'an District had the lowest NCSS (0.29t/hectare), behind Jiangbei District (0.37t/hectare), Shapingba District $(0.85 \mathrm{t} /$ hectare $)$ and Pengshui County (1.16t/hectare). The highest value is 11.62 times that of the lowest value. 


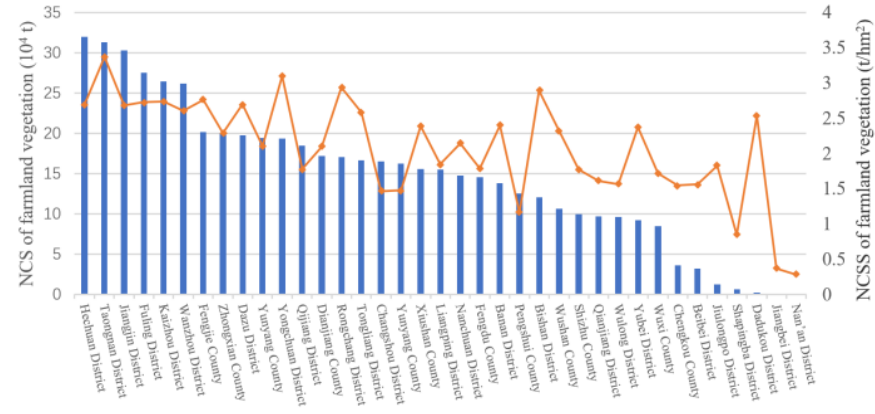

Total NCS $\rightarrow$ NCSS

Figure 6. District/county-level NCSs and NCSSs of Chongqing in 2017

To sum up, Tongnan District, Hechuan District, Jiangjin District and Dazu County have relatively high NCSs, NCSSs and carbon sink levels of farmland vegetation. It can be seen that, in these districts/counties, agricultural production features a large scale and high carbon efficiency; the farmland ecosystem can purify the GHGs released by secondary and tertiary industries to a certain extent, which promotes the carbon balance in the ecosystem.

On the contrary, Nan'an District, Jiangbei District and Shapingba District had relatively low NCSs, NCSSs and carbon sink levels of farmland vegetation. These districts mainly belong to the main city zone. Besides pursuing economic growth, the main city zone should fully utilize farmland vegetation, increase carbon sink efficiency and promote carbon balance in urban ecosystem.

\section{CONCLUSIONS}

(1) From 2000 to 2017, farmland vegetation in Chongqing had strong carbon sink function, and witnessed a continuous increase in carbon absorption (27.95\%) and NCS (33.23\%). In terms of NCS, southeast zone ranked the first, followed in turn by northeast zone, west zone and main city zone.

The farmland vegetation NCSS exhibited a growing trend: southeast zone remained on the top, followed in turn by northeast zone, west zone and main city zone. The minimal carbon absorption and minimal NCS in farmland vegetation appeared in 2001 and 2006, respectively, for the crop failure under dry weather.

Based on the lowest point of 2006, the evolution of farmland vegetation NCS can be divided into two phases: wavy decline from 2000 to 2006 and gradual increase from 2006 to 2017. The low carbon sink in 2006 is attributable to a severe drought. Except for that year, the NCSS remained high in west zone, thanks to the construction of Chongqing metropolitan area; the northeast zone, with better natural conditions than southeast zone, saw a continuous growth in farmland vegetation NCS under the policies on poverty alleviation.

(2) From 2011 to 2017, the source/sink structure of farmland vegetation remained stable in Chongqing. The main sources are pesticide and tillage, which account for $33 \%$ and $41 \%$ of total carbon emissions, respectively; the main sinks are corn, rice, vegetables and oil crops, which occupy $31 \%, 25 \%$, $13 \%$ and $10 \%$ of total carbon absorption, respectively.

The carbon absorption of vegetables increased dramatically by $149 \%$ from $586,399.43 \mathrm{t}$ in 2000 to $1,460,382.53 \mathrm{t}$ in 2007 , while that of oil crops also surged by $107 \%$ from $482,981.46 \mathrm{t}$ in 2000 to $1,000,956.27 \mathrm{t}$ in 2017 . Meanwhile, vegetables accounted for $10 \%$ of the total carbon absorption of farmland vegetation in 2000 , which rose by $104.71 \%$ to $20 \%$ in 2017 ; oil crops accounted for $8 \%$ of the total carbon absorption of farmland vegetation in 2000 , which rose by $9.91 \%$ to $14 \%$ in 2017. The main reason lies in the low economic benefits of grain crops and high economic coefficient of vegetables, because it is difficult to manage the fragmented lands intensively in mountainous regions of Chongqing; many farmers have shifted from food crops to cash crops like vegetables and oil crops, resulting in a continuous increase in the output of cash crops.

With socioeconomic development, urbanization has encroached some farmlands. In 2017, the farmland area in Chongqing dropped by $6.07 \%$ from the level of 2000 . As a result, rice, the main food crop in Chongqing, decreased by $11.16 \%$ in sown area, $2.95 \%$ in yield and carbon absorption, and $24.15 \%$ (from $28.48 \%$ to $21.6 \%$ ) in contribution to carbon absorption of farmland vegetation. By contrast, corn can adapt well to the local climate and terrain: the yield was growing slowly and steadily, the carbon absorption rose from $1,697,154.82 \mathrm{t}$ in 2000 to $2,287,681.30 \mathrm{t}$ in 2017 , and the contribution to carbon absorption of farmland vegetation climbed from $28.41 \%$ to $30.14 \%$.

(3) Generally speaking, farmland vegetation in Chongqing has absorbed much more carbon than the amount it emitted. This means farmland vegetation boasts powerful carbon sink function, and the farmland system enjoys high carbon efficiency. Both of them ease the environmental pressure from carbon emissions.

From 2000 to 2017, the farmland vegetation NCS of Chongqing mainly concentrated in the west zone and northeast zone; the NCS center of gravity shifted from the west zone to the northeast zone, and recently moved to the west zone.

The farmland vegetation NCSS in west zone was relatively high, thanks to the excellent location, high agricultural input, and advantageous social economy. The NCSS in northeast zone exhibited a growing trend. The NCSS in southeast zone remained stable on a low level, for the terrain of Chongqing is higher in the east and lower in the west.

To fully utilize the carbon sink function of farmland vegetation, the above zones must attach importance to ecological agriculture, protect farmland and modernize agriculture in future $[16,17]$. In the west zone, modern urban agriculture is developing rapidly, as evidenced by the growing investment in agriculture. Therefore, the farmland ecosystem in this zone has an ecological surplus, which is conducive to environment and ecology. However, the productivity and NCS are relatively low in the southeast zone, due to its relative poverty, mountainous landform and weak agriculture foundation.

(4) In Chongqing, farmland vegetation NCS and its center of gravity mainly lie in the west zone and northeast zone. In future, the two zones should focus on developing low-carbon industries and green agriculture. The government should guide farmland protection, giving fully play to the carbon sink function of farmland vegetation.

First, the government should improve agricultural technology and management, and develop green agriculture, enhancing the carbon absorption capacity.

Second, the government should encourage farmland protection to reduce erosion and improve soil fertility. Possible measures include zero tillage, protective agriculture, irrigation, rotation and so on.

Third, the government should increase crop yields by 
promoting good crop varieties. The southeast zone, as well as other zones with unfavorable landform, should elevate carbon sink function of farmland ecosystem through agroforestry.

Fourth, the government should strengthen land use management, evaluate organic carbon components in farmland soil, and improve the carbon management [24], thereby ensure carbon balance and ecological sustainability of farmland system.

(5) For the availability of data, the district/county-level NCS was only computed based on the main indices of source/sink structure. Many source/sink elements were not taken into account. The ignored elements may not affect the spatial distribution, but inevitably caused certain errors. The future research will collect even more data and try to increase the computing accuracy.

\section{ACKNOWLEDGMENT}

This paper is based on the Postdoctoral Research "Comparative study on the transformation and development of resource-exhausted cities in eastern and western China". Project supported by the Fundamental Research Funds for the Central Universities of Ministry of Education of China (Grant No. SWU1509447), Chongqing social science planning project (2019YBGL076), and Chongqing "University Innovation and Entrepreneurship Training Program" Project (S201910635049).

\section{REFERENCES}

[1] Le Noë, J., Billen, G., Mary, B., Garnier, J. (2019) Drivers of long-term carbon dynamics in cropland: A bio-political history (France, 1852-2014). Environmental Science \& Policy, 93: 53-65. https://doi.org/10.1016/j.envsci.2018.12.027

[2] Fu, Z., Stoy, P.C., Luo, Y., Chen, J., Sun, J., Montagnani, L., Wohlfahrt, G., Rahman, A.F., Rambalk, S., Bernhofer, B., Wang, J., Shirkey, G., Niu, S. (2017). Climate controls over the net carbon uptake period and amplitude of net ecosystem production in temperate and boreal ecosystems. Agricultural and Forest Meteorology, 243: 9-18. https://doi.org/10.1016/j.agrformet.2017.05.009

[3] Dissanayake, S., Mahadevan, R., Asafu-Adjaye, J. (2020). Evaluating the efficiency of carbon emissions policies in a large emitting developing country. Energy Policy, 136: 111080 https://doi.org/10.1016/j.enpol.2019.111080

[4] Xie, H., Zhang, Y., Choi, Y. (2018). Measuring the cultivated land use efficiency of the main grainproducing areas in China under the constraints of carbon emissions and agricultural nonpoint source pollution. Sustainability, 10(6): 1932-1963. https://doi.org/10.3390/su10061932

[5] Fan, J., McConkey, B.G., Liang, B.C., Angers, D.A., Janzen, H.H., Kröbel, R., Cerkowniak, D.D., Smith, W.N. (2019). Increasing crop yields and root input make Canadian farmland a large carbon sink. Geoderma, 336: 49-58. https://doi.org/10.1016/j.geoderma.2018.08.004

[6] Tian, Y., Zhang, J.B. (2013). Regional differentiation research on net carbon effect of agricultural production in China. Journal of Natural Resources, 28(8): 12981309. https://doi.org/1000-3037(2013) 08-1298-12
[7] Su, K., Wei, D., Lin, W. (2020). Influencing factors and spatial patterns of energy-related carbon emissions at the city-scale in Fujian province, Southeastern China. Journal of Cleaner Production, 244: 118840. https://doi.org/10.1016/j.jclepro.2019.118840

[8] Yin, Y.Y., Hao, J.M., Niu, L.A. (2016). Carbon cycle and carbon efficiency of farmland ecosystems in Quzhou, Hebei Province. Resources Science, 38(5): 918-928. https://doi.org/10.18402/resci.2016.05.11

[9] Howden-Chapman, P., Keall, M., Whitwell, K., Chapman, R. (2020). Evaluating natural experiments to measure the co-benefits of urban policy interventions to reduce carbon emissions in New Zealand. The Science of the Total Environment, 700: 134408. https://doi.org/10.1016/j.scitotenv.2019.134408

[10] Forsell, N., Korosuo, A., Gusti, M., Rüter, S., Havlik, P., Obersteiner, M. (2019). Impact of modelling choices on setting the reference levels for the EU forest carbon sinks: how do different assumptions affect the country-specific forest reference levels? Carbon Balance and Management, 14(1): 1-18. https://doi.org/10.1186/s13021-019-0125-9

[11] Pellis, G., Chiti, T., Rey, A., Curiel Yuste, J., Trotta, C., Papale, D. (2019). The ecosystem carbon sink implications of mountain forest expansion into abandoned grazing land: The role of subsoil and climatic factors. The Science of the Total Environment, 672: 106120. https://doi.org/10.1016/j.scitotenv.2019.03.329

[12] Li, S., Chen, P., Huang, J., Hsueh, M., Hsieh, L., Lee, C., Lin, H. (2018). Factors regulating carbon sinks in mangrove ecosystems. Global Change Biology, 24: 4195-4210. https://doi.org/10.1111/gcb.14322

[13] Acheampong, A.O., Boateng, E.B. (2019). Modelling carbon emission intensity: Application of artificial neural network. Journal of Cleaner Production, 225: 833-856. https://doi.org/10.1016/j.jclepro.2019.03.352

[14] Wu, Y., Tam, V.W.Y., Shuai, C., Shen, L., Zhang, Y., Liao, S. (2019). Decoupling China's economic growth from carbon emissions: Empirical studies from 30 Chinese provinces (2001-2015). The Science of the Total Environment, 656: 576-588. https://doi.org/10.1016/j.scitotenv.2018.11.384

[15] Mayer, S., Kühnel, A., Burmeister, J., Kögel-Knabner, I., Wiesmeier, M. (2019). Controlling factors of organic carbon stocks in agricultural topsoils and subsoils of Bavaria. Soil \& Tillage Research, 192: 22-32. https://doi.org/10.1016/j.still.2019.04.021

[16] da Silva Santana, M., Sampaio, E.V.D.S.B., Giongo, V., Menezes, R.S.C., de Jesus, K.N., de Albuquerque, E.R.G.M., do Nascimento, D.M., Pareyn, F.G.C., Cunha, T.J.F., Sampaio, R.M.B., Primo, D.C. (2019). Carbon and nitrogen stocks of soils under different land uses in Pernambuco state, Brazil. Geoderma Regional, 16: e00205. https://doi.org/10.1016/j.geodrs.2019.e00205

[17] Kay, S., Rega, C., Moreno, G., den Herder, M., Palma, J.H.N., Borek, R., Crous-Duran, J., Freese, D., Giannitsopoulos, M., Graves, A., Jäger, M., Lamersdorf, N., Memedemin, D., Mosquera-Losada, R., Pantera, A., Paracchini, M.L., Paris, P., Roces-Díaz, J.V., Rolo, V., Rosati, A., Sandor, M., Smith, J., Szerencsits, E., Varga, A., Viaud, V., Wawer, R., Burgess, P.J., Herzog, F. (2019). Agroforestry creates carbon sinks whilst enhancing the environment in agricultural landscapes in Europe. Land Use Policy, 83: 581-593. 
https://doi.org/10.1016/j.landusepol.2019.02.025

[18] Balsalobre-Lorente, D., Driha, O.M, Bekun, F.V., Osundina, O.A. (2019). Do agricultural activities induce carbon emissions? The BRICS experience. Environmental Science and Pollution Research International, 26: 25218-25234. https://doi.org/10.1007/s11356-019-05737-3

[19] Lv, W., Luo, C., Zhang, L., Niu, H., Zhang, Z., Wang, S., Wang, Y., Jiang, L., Wang, Y., He, J., Kardol, P., Wang, Q., Li, B., Liu, P., Dorji, T., Zhou, H., Zhao, X., Zhao, L. (2020). Net neutral carbon responses to warming and grazing in alpine grassland ecosystems. Agricultural and Forest Meteorology, 280: 107792. https://doi.org/10.1016/j.agrformet.2019.107792

[20] Rallings, A.M, Smukler, S.M, Gergel, S.E., Mullinix, K. (2019). Towards multifunctional land use in an agricultural landscape: A trade-off and synergy analysis in the Lower Fraser Valley, Canada. Landscape and Urban Planning, 184: 88-100. https://doi.org/10.1016/j.landurbplan.2018.12.013

[21] Jat, H., Datta, A., Choudhary, M., Yadav, A., Choudhary, V., Sharma, P., Gathala, M., Jat, M., McDonald, A. (2019). Effects of tillage, crop establishment and diversification on soil organic carbon, aggregation, aggregate associated carbon and productivity in cereal systems of semi-arid Northwest India. Soil \& Tillage Research, 190:

$128-138$ https://doi.org/10.1016/j.still.2019.03.005

[22] Vos, C., Don, A., Hobley, E.U., Prietz, R., Heidkamp, A., Freibauer, A. (2019). Factors controlling the variation in organic carbon stocks in agricultural soils of Germany. European Journal of Soil Science, 70: 550-564. https://doi.org/10.1111/ejss.12787
[23] Funes, I., Savé, R., Rovira, P., Molowny-Horas, R., Alcañiz, J.M., Ascaso, E., Herms, I., Herrero, C., Boixadera, J., Vayreda, J. (2019). Agricultural soil organic carbon stocks in the north-eastern Iberian Peninsula: Drivers and spatial variability. The Science of the Total Environment, 668: 283-294. https://doi.org/10.1016/j.scitotenv.2019.02.317

[24] Hertwich, E.G., Peters, G.P. (2009). Carbon footprint of nations: A global, trade-linked analysis. Environmental Science \& Technology, 43(16): 6414-6420. https://doi.org/10.1021/es803496a

[25] Robertson, G.P., Paul, E.A., Harwood, R.R. (2000). Greenhouse gases in intensive agriculture: contributions of individual gases to the radiative forcing of the atmosphere. Science, 289(5486): 1922-1925. https://doi.org/10.1126/science.289.5486.1922

[26] Xu, L., Yu, G., He, N. (2019). Increased soil organic carbon storage in Chinese terrestrial ecosystems from the 1980 s to the 2010s. Journal of Geographical Sciences, 29(1): 49-66. https://doi.org/10.11821/dlxb201811008

[27] Tian, Y., Chen, C.B. (2019). Effectiveness evaluation of carbon emission reduction in China, identification of backward areas and path optimization. Economic Management, 41(6): 22-37.

[28] Fan, J., McConkey, B.G., Liang, B.C., Angers, D.A., Janzen, H.H., Kröbel, R., Cerkowniak, D.D., Smith, W.N. (2019). Increasing crop yields and root input make Canadian farmland a large carbon sink. Geoderma, 336: 49-58. https://doi.org/10.1016/j.geoderma.2018.08.004

[29] Miao, G.Y., Yin, J., Zhang, Y.T., Zhang, A. (1998). Study on root growth of main crops in North China. Acta Agronomica Sinica, 24(1): 1-6. 